\title{
Larenks karsinomunu taklit eden bir olgu: Larenks tüberkülozu
}

\author{
A case mimicking carcinoma of larynx: Laryngeal tuberculosis
}

\author{
Aylin Gül, Salih Bakır*, Vefa Kınış, Musa Özbay, Gül Türkçü
}

Kulak Burun Boğaz Anabilim Dalı (Yrd. Doç. Dr. A. Gül, Yrd. Doç. Dr. S. Bakır, Yrd. Doç. Dr. V. Kınış, Yrd. Doç. Dr. M. Özbay), Patoloji Anabilim Dalı (Yrd. Doç. Dr. G. Türkçü), Dicle Üniversitesi Tıp Fakültesi, TR-21280 Diyarbakır

\section{Özet}

Larenks tüberkülozu, larenksin en sık granülomatöz enflamasyonudur. Hemen daima akciğer tüberkülozu ile beraberdir. Semptomların benzerliği ve kitlenin görünümü nedeniyle larenks maligniteleri ile karışabilir. Akciğer grafisi ve balgam kültürleri yararlı olsa da kesin tanı biyopsi ile konur. Günümüzde larenks tüberkülozu sıklığı azalmakla beraber, hala larenksin en sık granülomatöz hastalığı olmaya devam etmektedir. Ülkemiz gibi tüberkülozun hala ciddi bir sorun oluşturduğu gelişmekte olan ülkelerde, larengeal kitlelerin ayırıcı tanısında akılda tutulmalıdır. $\mathrm{Bu}$ yazıda larenks tüberkülozlu bir olgu sunulmuştur.

Anahtar sözcükler: Tüberküloz, larenks, larenks tüberkülozu

\begin{abstract}
Laryngeal tuberculosis is the most common granulomatous inflammation of the larynx. It is almost always associated with pulmonary tuberculosis. It may be confused with laryngeal malignancies due to similarity of symptoms and mass appereance. Pulmonary X-ray and positive sputum cultures contribute to the diagnosis but definitive diagnosis of the laryngeal tuberculosis is based on histopathologic findings of the biopsy specimen. Although laryngeal tuberculosis incidence declines, it is still the most common granulomatous inflammation of the larynx. It should be considered in differential diagnosis of laryngeal masses especially in developing countries like our country, which tuberculosis disease is stil common. In this article, a case of larynx tuberculosis is presented.
\end{abstract}

Keywords: Tuberculous, larynx, laryngeal tuberculosis

Geliş tarihi/Received: 04 Ekim 2012; Kabul tarihi/Accepted: 28 Ocak 2013

*İletişim adresi:

Dr. Salih Bakır, Kulak Burun Boğaz Anabilim Dalı, Dicle Üniversitesi Tıp Fakültesi, TR-21280

Diyarbakır. E-posta: drsalihbakir@gmail.com

\section{Giriş}

Tüberküloz larenjit, antitüberküloz tedavisinden önceki dönemlere göre sıklığı önemli oranda azalmış olmakla beraber, günümüzde hala larenksin en s1k granülomatöz hastalığıdır [1]. Her ne kadar sıklığı \%0,6 ile \%1,3 olarak bildirilse de bu rakamların gerçeği tam olarak yansıtmadığı düşünülmektedir $[2,3]$. Çünkü akciğer tüberkülozu tanılı olgularda ses kısıklığı gibi larengeal semptomlar olsa bile, tedavi protokolünü değiştirmeyeceği ve bulaşıcılık riskinin yüksek olduğu düşünüldüğünden, larenksin endoskopik bakısı ihmal edilmektedir. Sonuçta larenks tüberkülozlu olgular gözden kaçabilmektedir [3]. Oysaki postmortem akciğer tüberkülozlu olguların otopsi değerlendirmelerinde \%30 oranında larenks tüberkülozu tespit edilmiştir [4]. Ayrıca gelişmiş ülkelerde ciddi bir sorun oluşturan HIV infeksiyonlu olgularda larinks tüberkülozu \%5,5 oranında bildirilmektedir [5]. Dünya sağlık örgütünün 2010'da yayınladığı raporda; tüberküloz hastalığının dünya için halen çok ciddi bir sorun olduğunu vurgulamaktadır. Bu raporda; özellikle Asya kıtasını etkileyen bu olgunun yaygınlığının hızla artması yanında, bu hastaların dörtte birinin klasik tüberküloz 
tedavisine yanıt vermemesi ve direnç gelişmesi üzerinde durulmaktadır [6]. Ülkemizde bu olgunun tehdit ettiği coğrafyada yer almaktadır [7]. Bu durum önümüzdeki yıllarda oldukça sıkıntılı olan bu patoloji ile daha sık karşılaşılacağı anlamına gelmektedir. Laringeal tüberküloz, ülkemiz gibi tüberkülozun hala ciddi bir sorun oluşturduğu gelişmekte olan ülkelerde ayırıcı tanıda ilk başlarda düşünülmesi gereken bir patolojidir. $\mathrm{Bu}$ yazıda ses kısıklığı ve ağrılı yutma şikayeti ile gelen bir laringeal tüberküloz olgusu literatür eşliğinde sunulmuştur.

\section{Olgu sunumu}

Kırk dokuz yasındaki erkek olgu yaklaşık 3 aydır devam eden ses kısıklığı, yutma güçlüğü, odinofaji ve kilo kaybı şikayetleri ile başvurdu. Hastanın yapılan kulak burun boğaz muayenesi ve indirekt laringoskopik muayene neticesinde, epiglottisi tutup her iki ariepiglottik plikaya kısmen uzanan vejetan kitle saptandı (Resim 1). Glottik bölge, subglottik bölge, interaritenoid bölge ve her iki band ventrikülün salim olduğu görüldü. Öncelikle malignite düşünülen hasta direk laringoskopi ve biyopsi yapılmak üzere yatırıldı. Preoperatif tetkikler sırasında çekilen posteroanterior akciğer grafisinde her iki akciğerde yaygın retikülonodüler tarzda tutulum izlendi (Resim 2). Hasta Göğüs Hastalıkları'na konsulte edildi, toraks bilgisayarlı tomografisi önerildi. Sol akciğer üst lobdan alt lob süperior segmente uzanan kaviter lezyon ve sol akciğer ile sağ akciğer üst lob ve alt lob süperior segmentte küçük boyutlu konsolidasyon alanları, endobronşial yayılıma ait tomurcuklanmış ağaç görünümleri izlenmesi nedeniyle görünümün aktif primer tüberküloz ile uyumlu olduğu rapor edildi (Resim 3). Süspansiyon mikrolarengoskopisi ile alınan biyopsi spesmenlerin histopatolojik incelemesinde merkezinde kazeifikasyon nekrozu içeren granülomlar izlendi (Resim 4). Ziehl-Neelsen boyası ile spesmende ARB görülmedi. Balgam direkt bakısında ARB görüldü. BCG aşısı (+) olan olgu yapılan tüberkülin testinde PPD; $11 \mathrm{~mm}$ olarak ölçüldü. Eritrosit sedimantasyon hızı $48 \mathrm{~mm} / \mathrm{saat}$ olarak saptandı. Hastada mevcut klinik ve radyolojik bulgular eşliğinde larengeal tüberküloz-pulmoner tüberküloz düşünüldü. Antitüberküloz ilaçlarla tedaviye baslandı. İzoniyazid; $5 \mathrm{mg} / \mathrm{kg} /$ gün (max. $300 \mathrm{mg} /$ gün), Rifampisin; $10 \mathrm{mg} / \mathrm{kg} /$ gün (max. 600mg/gün), Pirazinamid; 25mg/kg/gün (max. 2000mg/gün), Etambutol; $15 \mathrm{mg} / \mathrm{kg} /$ gün (max. 1500mg/gün) şeklinde günlük ilaç dozları ayarlandı. Tedavi yanıtı çok iyi olarak izlendi.

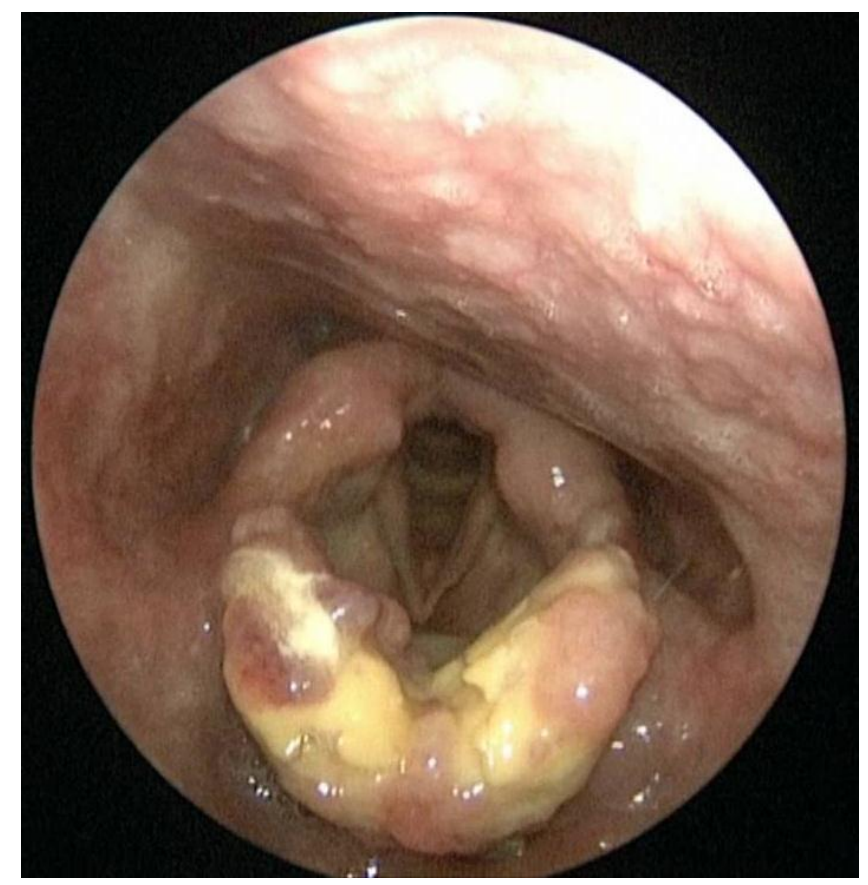

Resim 1. Epiglotisi tutup ariepiglottik plikalara uzanan vejetan kitlenin larengoskopik görünümü. 


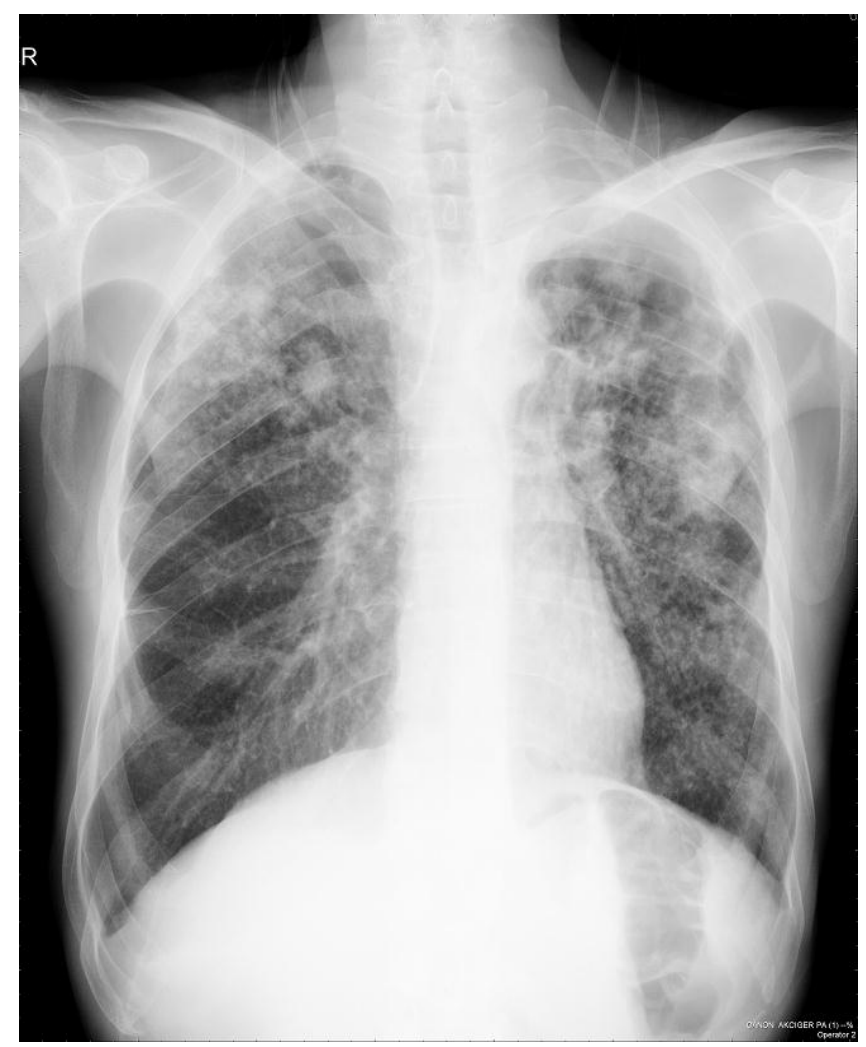

Resim 2. Olgunun direkt akciğer radyografisi.

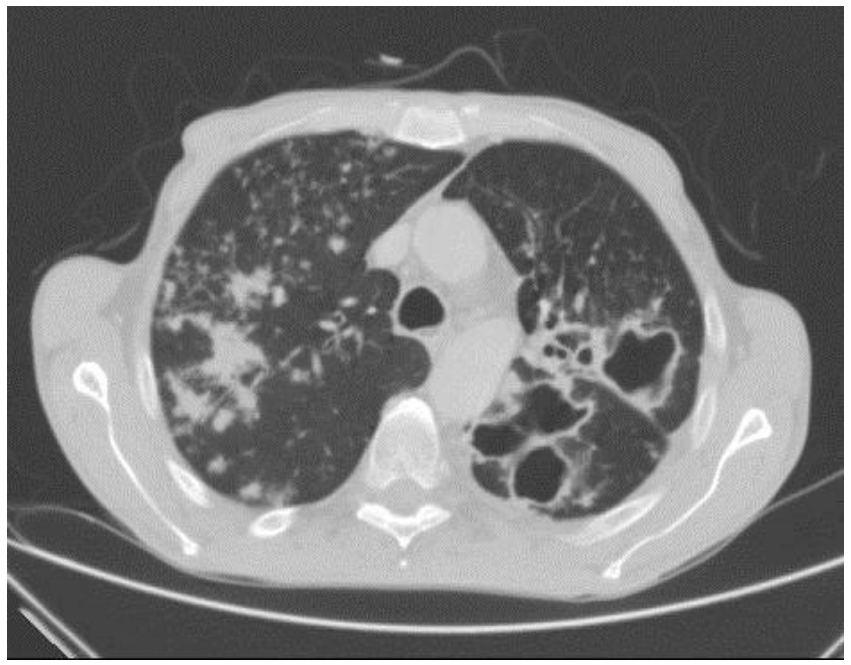

Resim 3. Olgunun toraks bilgisayarlı tomografi kesiti. 


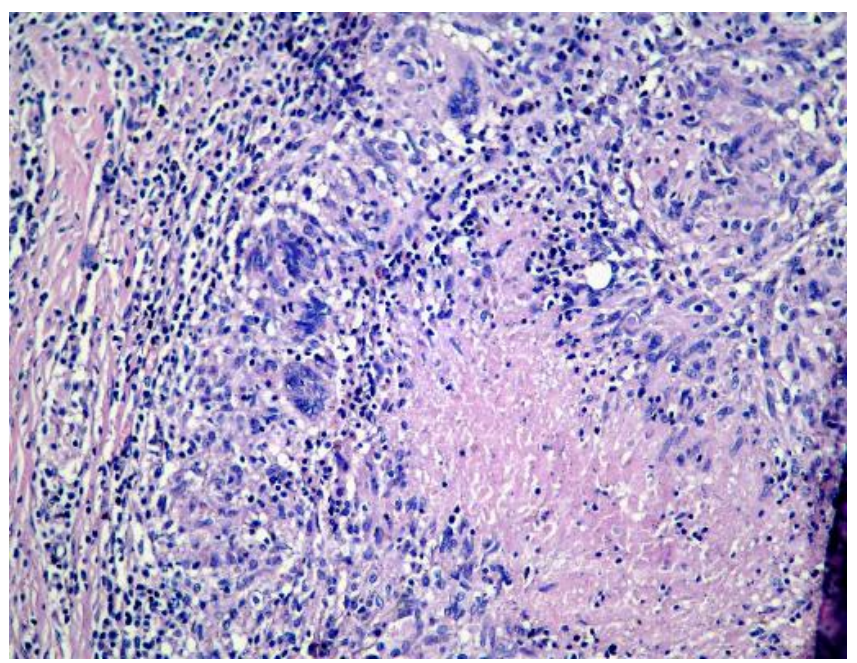

Resim 4. Histopatolojik incelemede merkezinde kazeifikasyon nekrozu içeren granülom yapısı (H\&E x 200).

\section{Tartışma}

Larengeal tüberküloz, 5. ve 6. dekadlarda ve erkeklerde $(\mathrm{E} / \mathrm{K}=2 / 1)$ daha s1k görülmektedir [8]. Hemen her zaman aktif akciğer tüberkülozu ile birliktedir [3]. Basilin infekte balgam aracılığıyla endobronşial sistemden larenkse direkt olarak yayılması (bronkojenik teori) en çok kabul gören teoridir [10]. Bir diğer teori ise akciğerdeki tüberküloz enfeksiyonunun hematojen veya lenfojen yolla larenkse ulaşmasıdır [10]. Akciğer tutulumu saptanmayan "primer larengeal tüberküloz" olguları oldukça nadir görülmekte ve hematojen yayılıma bağlanmaktadır [3].

Glottik veya transglottik yerleşim görülmekle beraber en s1k supraglottik bölge (epiglottis, ariepiglottik plika ve bant ventrikül) tutulmaktadır [1,3]. Genelde supraglottik yapıların tutulması nedeniyle en s1k rastlanan semptomlar, bizim olgumuzda olduğu gibi, ses kısıklığı ve ağrılı yutmadır [1, 3, 10]. Larengeal tüberkülozda enfeksiyon subepitelyal alanda eksudasyon ile başlar bunu yuvarlak hücre infiltrasyonu izler ve sonuçta fibrozisle iyileşme gözlenir. Kord vokallerin lamina propria tabakasında da fibrotik değişiklikler olabilir. $\mathrm{Bu}$ değişiklikler vibrasyonda olumsuz etki yaparak ses kalitesinde geri dönüşümsüz değişikliklere neden olabilir [11]. Bizim hastamızda epiglot larengeal yüzünden kaynaklı lezyonu vardı. Buna bağlı olarak ses kısıklığı olan hastamızın tedaviden sonraki dönemde lezyonun gerilemesi ile beraber șikayeti kısmen gerilemiști. Ayrıca akciğer tüberkülozunda sıklıkla görülen prodüktif öksürük, ateş, kilo kaybı ve gece terlemeleri gibi semptomlar olabilir [10]. Laringoskopik muayenede mukozal hiperemi, ödem, ülserler veya bazen obstrüksiyona bile yol açan kitleler şeklinde karşımıza çıkabilir. Tipik bir görünümü yoktur [10].

Tanı; klinik bulgular yanında balgam kültürü, PPD testi, akciğer grafisi ve lezyondan alınan biyopsinin histopatolojik incelemesi ile konmaktadır [1]. Akciğer tüberkülozunun eşlik ettiği olgularda tanı daha kolay olabilir. Ancak balgam yaymasında Mycobacterium tuberculosis'in gösterilmesi veya kültürde üretilmesi tanı için her zaman yeterli değildir. Zaten her zaman direkt mikroskopide Ziehl-Neelsen boyası ile basil saptanamamaktadır. Başta malignite olmak üzere görünüm olarak karışabilecek olguları dışlamak için mutlaka histopatolojik inceleme yapılmalıdır [9]. Histopatolojik incelemede; santralinde kazeifikasyon nekrozu gösteren granülom yapıları tipiktir, Langhans tipi dev hücreler görülebilir $[1,3,10]$.

Larengeal tüberküloz tanısını koyarken lezyonun larenks kanseri ile ayırıcı tanısının yapılması gerekir. Çünkü lezyon görünüm ve klinik olarak kanseri taklit edebilir. $\mathrm{Bu}$ olguda olduğu gibi, genelde sigara içen orta-ileri yaştaki erkeklerde görülmesi, ses 
kısıklığına yol açması ve fizik muayenede larengeal kitlenin görünümü öncelikle maligniteden şüphelenilmesine neden olur. Bizim olgumuzda ilk başvuru anında ön tanı olarak larenks kanseri düşünülmekteyken, çekilen postero-anterior akciğer radyogramındaki görünüm ve daha sonra anamnezin derinleştirilmesiyle akciğer tüberkülozunda görülen semptomların olması ayırıcı tanıda larengeal tüberkülozu akla getirmiştir.

Yapılan balgam kültüründe bakteriyolojik pozitiflik görülmesi (ARB pozitifliği) ve biyopsinin histopatolojik incelemesi neticesinde maligniteden uzaklaşılmış, larenks tüberkülozu düşünülmüştür. Malignite dışında ayırıcı tanıda kronik larenjit, sarkoidoz, lepra, sifiliz, Wegener ve mantar enfeksiyonlarıda unutulmamalıdır [1].

Tedavide akciğer tüberkülozu için gereken uygun tüberküloz ilaçları kullanılır [1, 3, 10]. Larenks tüberkülozu görülmesi, akciğer tüberkülozu tedavisinde değişiklik yapmayı gerektirmez [10]. Günümüzde hala larenks tüberkülozu, standart tüberküloz tedavisine çok iyi yanıt vermektedir [3]. Ancak antitüberküloz ilaçlara karşı artan direnç gelişimi, gelecekte larinks tüberkülozu tedavisinde alternatif metodları gerektirebilir.

\section{Kaynaklar}

1. Erdem T, Miman MC, Gürses İ, Kızılay A, Karataş E, Türker G. Tüberküloz larenjitleri. KBB ve BBC Dergisi 2003; 11: 68-72.

2. Vidal R, Mayordomo C, Miravitlles M, Martí S, Torrella M, Lorente J. Pulmonary and laryngeal tuberculosis. Study of 26 patients. Rev Clin Esp 1996; 196: 378-80.

3. Tatar D, Çırak K, Ertuğrul G, Özacar R, Halilçolar H, Yener AG. Larinks tüberkülozu olgularimiz. Solunum Hastalıkları 2000; 11: 212-6.

4. Soda A, Rubio H, Salazar M, Ganem J, Berlanga D, Sanchez A. Tuberculosis of the larynx: clinical aspects in 19 patients. Laryngoscope 1989; 99: 1147-50.

5. Singh B, Balwally AN, Nash M, Har-El G, Lucente FE. Laryngeal tuberculosis in HIV-infected patients: A difficult diagnosis. Laryngoscope 1996; 106: 1238-40.

6. Guidelines for the surveillance of drug resistance in tuberculosis - 4th ed. Geneva, World Health Organization, 2010 (WHO/HTM/TB/2009.422; Accessed March 21, 2012)

7. Yıldız T, Akyıldız L, Ateş G. Batman Verem Savaşı Dispanseri'nde 2003 yılında takip edilen tüberküloz olgularının analizi. Dicle Tıp Derg 2007; 34: 20-4.

8. Nishiike S, Irifune M, Doi K, Sawada T, Kubo T. Laryngeal tuberculosis: a report of 15 cases. Ann Otol Rhinol Laryngol 2002; 111: 916-8.

9. Ramadan HH, Tarazi AE, Baroudy FM. Laryngeal tuberculosis: presentation of 16 cases and review of the literature. J Otolarnyngol 1993; 22: 39-41.

10. Şakar A, Yorgancıoğlu A, Çelik P, Çelik O, Ünlü H, Ayhan S, Demir A. Farenks ve larenks tüberkülozu (iki olgu nedeniyle). Solunum 2002; 4: 51-5.

11. Özüdoğru E, Çaklı H, Altuntaş EE, Gürbüz MK. Effects of laryngeal tuberculosis on vocal fold functions: case report. Acta otorhinolaryngol Ital 2005; 25: 374-7. 